\title{
Use of reactive MgO-activated slag in high sulphide-bearing lead-zinc cemented backfill
}

\author{
U Guo BGRIMM Technology Group, China \\ WC Li BGRIMM Technology Group, China
}

A Pan Lassonde Institute of Mining, University of Toronto, Canada

GS Liu BGRIMM Technology Group, China

WY Xu BGRIMM Technology Group, China

\begin{abstract}
The long-term strength of cemented backfill mass with ordinary Portland cement binder generally decreases with sulphide content due to the formation of expansive phases such as gypsum. This paper investigates the potential of using commercial reactive $\mathrm{MgO}$-activated ground granulated blast furnace slag (MgO-GGBS) in cemented backfill from high sulphide content lead-zinc mine tailings to prevent long-term strength loss. The study focuses on the effect of $\mathrm{MgO}-G G B S$ content and the reactive $\mathrm{MgO}$ dosage on the unconfined compressive strength (UCS) and the shrinkage/expansion rate. The test results showed that the 28-day UCS of cemented backfill achieved the target strength ( $\geqq 1.0 \mathrm{MPa}$ ) with 14 wt\% MgO-GGBS content, and the reactive $\mathrm{MgO}$ dosage affected the long-term UCS and the shrinkage/expansion rate of cemented backfill body. The main hydration products when using MgO-GGBS were hydrated calcium/magnesium silicate (C-S-H/M-S$\mathrm{H})$ and hydrotalcite-like phases (Ht). Cemented backfill has a porous opening microstructure. Micro-expansion produced by appropriate $\mathrm{MgO}$ content can increase microstructure density, which increases short- and long-term UCS of cemented backfill body, while sustained expansion produced by excessive MgO could destroy the MgO-GGBS microstructure, decreasing the UCS of cemented backfill. We conclude that the mechanical and extension properties of cemented backfill body are highly dependent on the reactive MgO content of the MgO-GGBS. The optimum value of responsive $\mathrm{MgO}$ content of MgO-GGBS was 2.5-7.5 wt\% to achieve the long-term stability of cemented backfill.
\end{abstract}

Keywords: cemented backfill, slag binder, unconfined compressive strength, shrinkage rate, microstructure

\section{Introduction}

In China, lead-zinc overflow tailings containing sulphides are usually stored directly on the ground surface. Such tailings are easily oxidised in the air and susceptible to acid mine drainage generation. These conditions often result in the release of metal ions to the surrounding environment (Ying et al. 2018; Shiyang 2015; Qinhua et al. 2017). Environmental pollution caused by sulphide-bearing lead-zinc tailings can be effectively eliminated by aggregating the residuals with the proper amount of binder to form a cemented backfill body. In past decades, researchers have studied cemented paste fillings preparation using sulphide-bearing tailings as the aggregate, and the optimal mixing ratio of cement, the mineral additives and water. However, Benzaazoua et al. (1999) found that when sulphide-bearing tailings are used as the aggregate, the sulphate in the cemented backfill body reacts with the cement hydration product, generating an expansive product that leads to cracking of the cemented backfill body. Based on sulphur content, the authors categorised tailings into low-sulphur tailings ( $<<5 \mathrm{wt} \%$ ), medium-sulphur tailings (5-20 wt\%), and high-sulphur tailings (>20 wt\%) (Benzaazoua et al. 2002). For low- and medium-sulphur tailings, slag-based binders show greater cementing power than Portland cement and fly ash-based cement. Kesimal et al. (2004) argued that tailings components such as pyrite $\left(\mathrm{FeS}_{2}\right)$ could be oxidised to sulphate under the joint action of water and air, while sulphate can reduce the long-term strength of a cemented backfill body. In their study, the 180-day strength 
of a test block was decreased by $40-42 \%$ compared with that of the control group. Ercikdi reported that when tailings with sulphides are used as aggregates, the addition of volcanic admixtures (such as fly ash, slag powder, and silica fume) can reduce the reduction of the long-term compressive strength of the backfill mass (Ercikdi et al. 2009, 2010).

Jiaguo and Desheng (2003) found that the sulphur content in tailings had a significant impact on the 90-day compressive strength of a cemented backfill body. The presence of low-sulphur content in tailings increased their compressive strength. The research of Bao et al. indicated that, for high levels of sulphides in tailings, the generated sulphate can reduce the long-term strength of a cemented backfill body while a higher saturation reduces the reaction rate of sulphides in tailings (Bao \& Huyuan 2003). Zheng et al. showed that the application of slag-based cement or the addition of limestone powder and water reducer could consolidate low- and medium-sulphur coarse tailings as well as full tailings without reducing long-term compressive strength (cured to 360 days). For medium-sulphur fine tailings, the compressive strength of the solidified body began to decline after 28 days, whether ordinary cement or slag-based cement was used, showing a reduction of over $80 \%$ in compressive strength after 360 days (Zheng et al. 2016, 2017, 2018).

Reactive MgO-GGBS is a neotype alkali-activated cementing material (Jin et al. 2014, 2015). However, the preparation of cemented backfill body from sulphide-bearing lead-zinc tailings using reactive MgO-GGBS as the binder has not been reported.

The main objectives of this study are as follows:

- Investigate the effect of MgO-GGBS dosage on 28-day unconfined comprehensive strength (UCS) of cemented backfill body.

- Investigate the effect of reactive MgO content in MgO-GGBS on UCS development and shrinkage/expansion rate of cemented backfill body.

- Investigate the mechanism of the short- and long-term strength and stability of cemented backfill body using reactive $\mathrm{MgO}-\mathrm{GGBS}$ binder.

\section{$2 \quad$ Materials and methods}

\subsection{Materials}

Tailings: The tailings selected in this paper are fine tailings (also known as overflow tailings) taken from a lead-zinc ore in South China. The essential minerals of the tailings are quartz, pyrite, calcite, dolomite, and mirrorstone in Figure 1. The particle size distribution of tailings was obtained by laser image analysis. The physical and chemical properties of the tailings are shown in Table 1 and Table 2 . The sulphur content of the tailings is $19.07 \%$ (middle content tailings). The SSA of the fine tailings is the largest in raw materials. The solid content of fine tailings transported from the mine to the laboratory is $63 \mathrm{wt} \%$. 


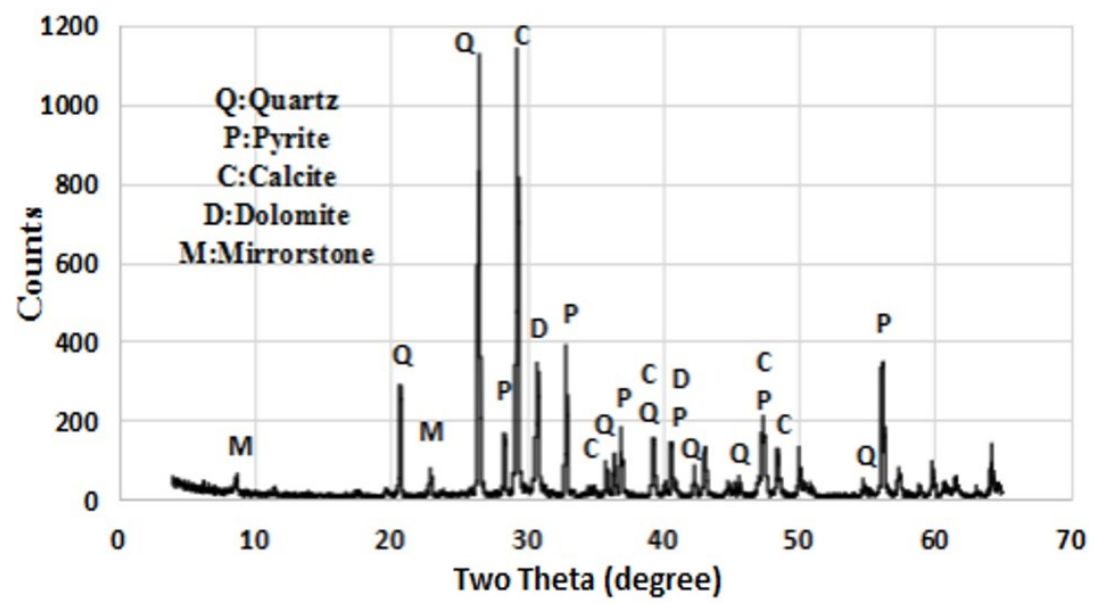

(a)

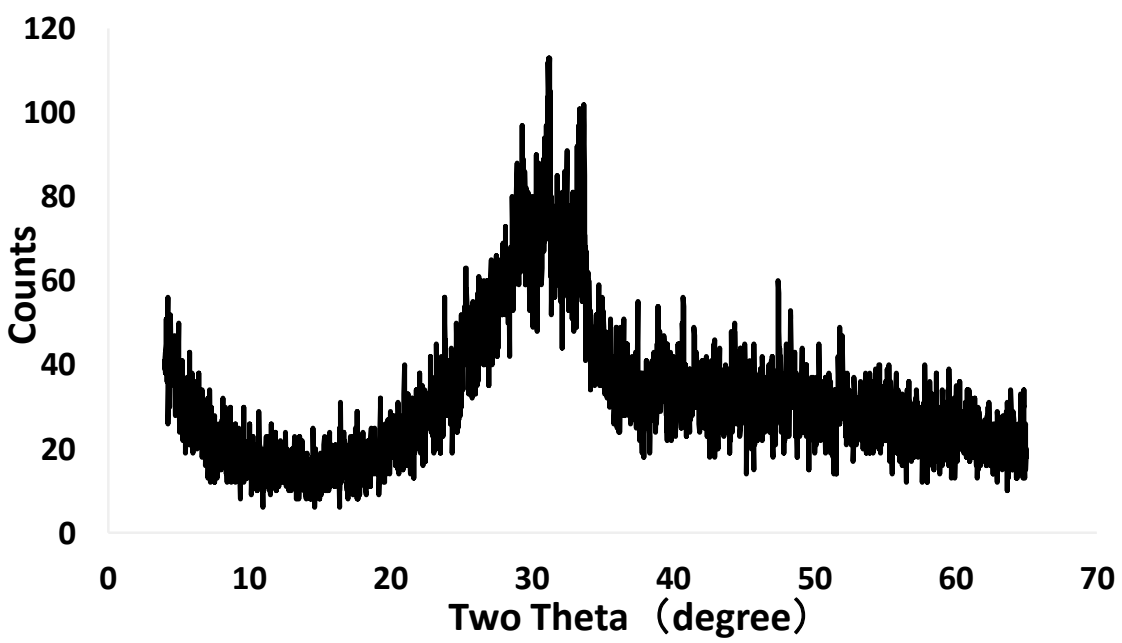

(b)

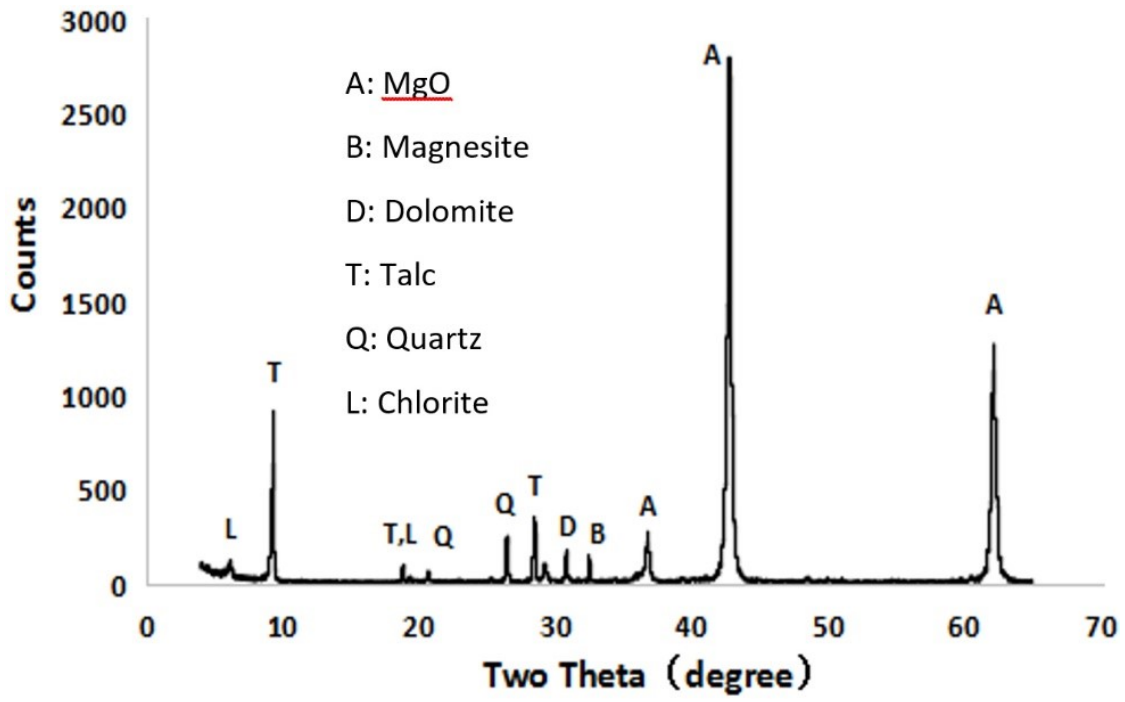

(c)

Figure 1 (a) X-ray diffraction profiles of tailings; (b) GGBS; (c) MgO 
Table 1 Chemical properties of binder and tailings

\begin{tabular}{lllllllllll}
\hline $\begin{array}{l}\text { Chemical } \\
\text { composition }\end{array}$ & $\begin{array}{l}\mathrm{SiO}_{2} \\
(\%)\end{array}$ & $\begin{array}{l}\mathrm{Al}_{2} \mathrm{O}_{3} \\
(\%)\end{array}$ & $\begin{array}{l}\mathrm{FeO} \\
\mathbf{( \% )}\end{array}$ & $\begin{array}{l}\mathrm{CaO} \\
(\%)\end{array}$ & $\begin{array}{l}\mathrm{MgO} \\
(\%)\end{array}$ & $\begin{array}{l}\mathrm{Pb} \\
(\%)\end{array}$ & $\begin{array}{l}\mathrm{Zn} \\
(\%)\end{array}$ & $\begin{array}{l}\mathrm{Cu} \\
(\%)\end{array}$ & $\begin{array}{l}\mathrm{S} \\
(\%)\end{array}$ & $\begin{array}{l}\text { Loss } \\
(\%)\end{array}$ \\
\hline Tailings & 25.37 & 5.88 & 14.28 & 12.47 & 0.15 & 0.84 & 0.54 & 0.28 & 19.07 & 19.97 \\
GGBS & 31.68 & 12.77 & 2.02 & 40.80 & 4.76 & - & - & - & 0.84 & - \\
MgO & 2.22 & 1.29 & 0.90 & 4.40 & 88.80 & - & - & - & - & 2.14 \\
\hline
\end{tabular}

SSA stands for specific surface area. Gs stands for specific gravity.

Table 2 Physical properties of binder and tailings

\begin{tabular}{llllllllll}
\hline $\begin{array}{l}\text { Physical } \\
\text { properties }\end{array}$ & $\begin{array}{l}\text { SSA } \\
\left(\mathbf{m}^{2} / \mathbf{k g}\right)\end{array}$ & $\begin{array}{l}\mathrm{Gs} \\
(-)\end{array}$ & $\begin{array}{l}>90 \\
(\%)\end{array}$ & $\begin{array}{l}>45 \\
(\%)\end{array}$ & $\begin{array}{l}\mathrm{D}_{10} \\
(\boldsymbol{\mu m})\end{array}$ & $\begin{array}{l}\mathrm{D}_{60} \\
(\boldsymbol{\mu m})\end{array}$ & $\begin{array}{l}\mathrm{Cu} \\
(-)\end{array}$ & $\begin{array}{l}\mathrm{Cc} \\
(-)\end{array}$ & $\begin{array}{l}<20 \mu \mathrm{m} \\
(\%)\end{array}$ \\
\hline Tailings & 633.8 & 3.00 & 1.07 & 7.28 & 1.50 & 14.68 & 9.8 & 0.94 & 73.67 \\
GGBS & 454.7 & 2.90 & 0 & 5.0 & 6.47 & 19.99 & 2.1 & 1.11 & 62.15 \\
MgO & 538.9 & 2.94 & 2.69 & 21.96 & 1.60 & 27.8 & 17.4 & 2.03 & 48.62 \\
\hline
\end{tabular}

The binder used in this study is a complex binder comprised of GGBS and reactive MgO. The physical and chemical properties of GGBS and reactive MgO are shown in Tables 1 and 2.

The GGBS used in this paper is a grade 595 product on the market. In China, GGBS is divided into three grades (i.e. S105, S95 and S75) according to the activity index of GGBS. S95 grade GGBS shows that the 28-day mortar (i.e. standard sand) strength of the compound of the GGBS and the control cement (i.e. 100\% Portland cement) of mass ratio $1: 1$ is $\geq 95 \%$ that of the control cement at the same mortar fluidity.

The reactive $\mathrm{MgO}$ used in this research is from a Chinese supplier and has an activation time of $33.5 \mathrm{~s}$. The $\mathrm{MgO}$ activity in this research was determined based on the time required for $\mathrm{MgO}$ to neutralise a citric acid solution to the phenolphthalein endpoint. The test was performed as follows. An MgO sample (1.7 g) was weighed and transferred into a dry flask $(300 \mathrm{~mL})$. The flask was set on a thermostatic $40^{\circ} \mathrm{C}$ magnetic mixer, and the $\mathrm{MgO}$ was rapidly mixed with $200 \mathrm{~mL}$ of $40^{\circ} \mathrm{C}$ citric acid solution $(0.07 \mathrm{~mol} / \mathrm{L})$ in the presence of two drops of phenolphthalein. The stopwatch was started, and the magnetic mixer was turned on (about $500 \mathrm{r} / \mathrm{s}$ ). The stopwatch was immediately read when the solution turned red. The number of seconds describes the $\mathrm{MgO}$ activity. The shorter the time was correlated to the higher the $\mathrm{MgO}$ reactivity.

The mixing material reaches the designed slump and needs to be replenished. The new mixture of water in this paper is the public tap water.

\section{$2.2 \quad$ Methods}

\subsubsection{Mixture proportion and test sample preparation}

The mix proportion and partial performance of the mix are shown in Table 3. A total of 96 cubic samples were subjected to UCS tests after 14, 28, 56, 90, 180 and 360 days of curing periods. A total of 12 prism samples were subjected to shrinkage or expansion rate measurement from seven to 360 days of curing periods. 
Table 3 Mix proportions and partial properties of the mixtures

\begin{tabular}{lllllllll}
\hline No. & \multicolumn{3}{c}{ Percentage of mixture } & \multicolumn{3}{c}{ Partial properties of the mixture } \\
\hline & $\begin{array}{l}\text { Wet tailings } \\
\text { /g }\end{array}$ & $\begin{array}{l}\text { GGBS } \\
\text { /g }\end{array}$ & $\begin{array}{l}\text { MgO } \\
\text { /g }\end{array}$ & $\begin{array}{l}\text { Water } \\
\text { /g }\end{array}$ & $\begin{array}{l}\text { Solid } \\
\text { content } \\
\text { /\% }\end{array}$ & $\begin{array}{l}\text { W/B } \\
\text { ratio }\end{array}$ & $\begin{array}{l}\text { Slump } \\
\text { /mm }\end{array}$ & $\begin{array}{l}\text { Bleeding } \\
\text { rate/\% }\end{array}$ \\
\hline B10M2.5 & 1,000 & 68.25 & 1.75 & 64.5 & 61.7 & 6.21 & 180 & 2.8 \\
B10M5 & 1,000 & 66.5 & 3.5 & 62.7 & 61.8 & 6.18 & 180 & 2.5 \\
B10M7.5 & 1,000 & 64.75 & 5.25 & 57.2 & 62.1 & 6.10 & 180 & 2.0 \\
B10M10 & 1,000 & 63.0 & 7.0 & 59.0 & 62.0 & 6.13 & 180 & 1.5 \\
B12M2.5 & 1,000 & 83.85 & 2.15 & 72.5 & 61.8 & 5.15 & 180 & 2.5 \\
B12M5 & 1,000 & 81.7 & 4.3 & 76.3 & 61.6 & 5.19 & 180 & 2.3 \\
B12M7.5 & 1,000 & 79.55 & 6.45 & 68.8 & 62.0 & 5.10 & 180 & 2.0 \\
B12M10 & 1,000 & 77.4 & 8.6 & 74.6 & 61.7 & 5.17 & 180 & 1.5 \\
B14M2.5 & 1,000 & 100 & 2.5 & 84.6 & 61.7 & 4.44 & 180 & 2.0 \\
B14M5 & 1,000 & 97.3 & 5.2 & 78.9 & 62.0 & 4.38 & 180 & 1.8 \\
B14M7.5 & 1,000 & 94.8 & 7.7 & 80.9 & 61.9 & 4.40 & 180 & 1.5 \\
B14M10 & 1,000 & 92.1 & 10.4 & 80.9 & 61.9 & 4.40 & 180 & 1.0 \\
\hline
\end{tabular}

The test samples were prepared as follows. The wet tailings, GGBS, reactive $\mathrm{MgO}$ and water were combined in an agitating pan according to the specified requirements and proportions. Self-motion stirring of the mortar agitator was applied (low speed for $60 \mathrm{~s}$, high speed for $30 \mathrm{~s}$, stop for $90 \mathrm{~s}$, and repeat at high speed for 60 to $240 \mathrm{~s}$ in total). Once formed, the mix was cast into the cubic $(70.7 \times 70.7 \times 70.7 \mathrm{~mm})$ or prism $(40 \times 40 \times 160 \mathrm{~mm})$ mould in two layers and hand-vibrated to eliminate voids. The samples in moulds were stored below $20 \pm 5^{\circ} \mathrm{C}$ and relative humidity of $50 \pm 5 \%$ and covered with cling film to avoid moisture change. After 7 days, the samples were demoulded, and stored below $20 \pm 2^{\circ} \mathrm{C}$ and relative humidity of $90 \pm 2 \%$.

The shrinkage/expansion rate measurement was performed using a length comparator to determine the linear dimension variation of the sample along the longitudinal axis. The first reading was recorded immediately after demoulding, and the measurement was conducted in triplicate for each mix every two days for the first two weeks and then at 28, 56, 90, 180 and 360 days.

The UCS tests were done using the method stipulated in the test method for the strength of cement mortars which is the ISO method (GB17671-1999), but the actual compression area of the test sample should be measured.

The objective of this study is to reach 28-day UCS with a minimum of $1 \mathrm{MPa}$ as well as achieve long-term stability according to the requirements for mining technology.

\subsubsection{X-ray diffraction, mercury intrusion porosimeter and scanning electron microscope analysis}

After being UCS tested at the specified curing age, representative samples were taken from the surface and centre of the demoulded sample body for chemical analysis. The samples were soaked with acetone for 24 hours to end the hydration reaction of the binder and then oven-dried at $60^{\circ} \mathrm{C}$ for X-ray diffraction (XRD) analysis, mercury intrusion porosimeter (MIP) and scanning electron microscope (SEM) studies.

The XRD analysis was done using a Japanese XRD analysis meter of D/Max-2500 PC with the copper target on scanning angle $2 \theta$ ranging from $4^{\circ}$ to $60^{\circ}$ and a scanning speed of $2^{\circ}$ per minute. 
The MIP was analysed according to the ISO 15901-1:2005 standard (ISO 2005). In this study, mercury surface tension $\sigma$ and mercury contact angle $\theta$ were taken at 485 dynes $/ \mathrm{cm}$ and $130^{\circ} \mathrm{C}$, respectively.

\section{$3 \quad$ Results and discussion}

\subsection{Effect of MgO-GGBS dosage on 28-day UCS of cemented backfill body}

The effect of MgO-GGBS dosage on 28-day UCS of cemented backfill body is presented in Figure 2. The compressive strength of the cemented backfill body increases with MgO-GGBS content. This trend is illustrated in 2.5, 5.0, 7.5 and $10 \% \mathrm{MgO}$ contents cemented backfill. The 28-day compressive strength of the cemented backfill body is lower than the target compressive strength ( $\geq 1.0 \mathrm{MPa})$. At $12 \% \mathrm{MgO}-\mathrm{GGBS}$ dosage and $\mathrm{MgO}$ contents of 2.5 and $5.0 \%$, the 28-day compressive strength of the cemented backfill body is lower than the target compressive strength in Figures 2(a) and (b); at MgO contents of 7.5 and $10 \%$, the 28-day compressive strength of the cemented backfill body achieves the target in Figures 2(c) and (d). At $14 \%$ MgO-GGBS dosage and MgO contents of 2.5, 5.0, 7.5 and 10\%, the 28-day compressive strength of the cemented backfill body achieves the target.

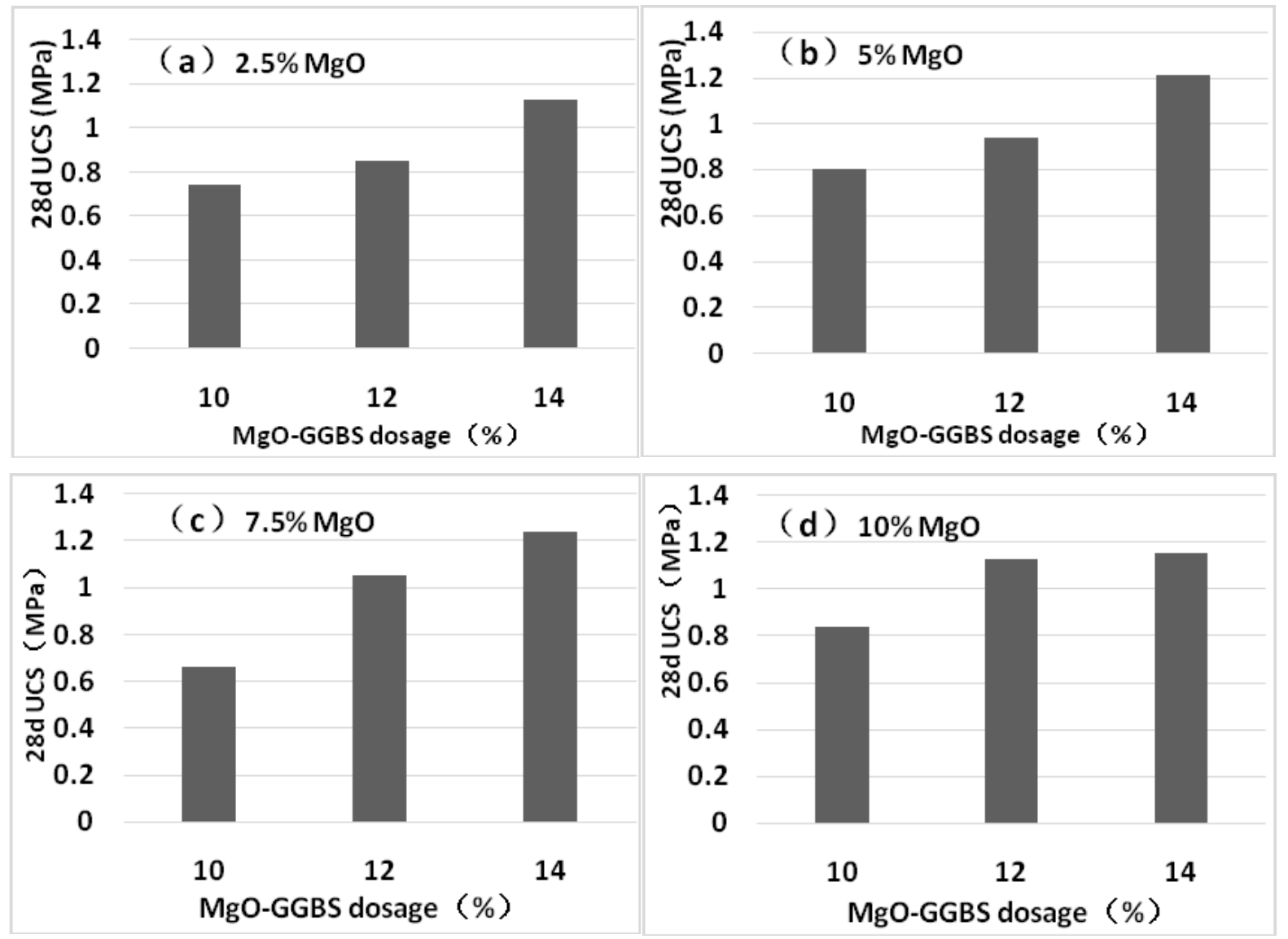

Figure 2 Effect of MgO-GGBS dosage on 28-day UCS of cemented backfill body

\subsection{Effect of MgO content on UCS development of cemented backfill body}

When MgO-GGBS dosage is $14 \%$ of the total solid mass (including tailings, MgO and GGBS), the proportion of reactive $\mathrm{MgO}$ affects the compressive strength of the cemented backfill body. As shown in Figure 3 , when the MgO-GGBS dosage is $14 \%$ with responsive $\mathrm{MgO}$ contents of 2.5, 5.0, 7.5 and $10 \%$, the 28 -day compressive strengths of the cemented backfill body are 1.244, 1.541, 1.472 and $1.487 \mathrm{MPa}$, respectively, while the 360-day compressive strengths are $3.315,3.462,3.550$ and $1.720 \mathrm{MPa}$, respectively. The compressive strength of the cemented backfill body increased by 166, 125, 141 and 15.7\% from 28 to 360 days with 2.5, 5.0, 7.5 and $10 \% \mathrm{MgO}$ contents, respectively. When the reactive MgO content is $10 \%$, the pre-90 day 
compressive strength of the cemented backfill body gradually increases to $2.506 \mathrm{MPa}$ at 90 days and then decreases to $1.72 \mathrm{MPa}$ at 360 days. The compressive strength of the cemented backfill body decreased $31.4 \%$ from 90 to 360 days. Therefore, when the MgO-GGBS dosage is $14 \%$, and the reactive $\mathrm{MgO}$ content varies from 2.5-7.5\%, the 28-day compressive strength of the cemented backfill body achieves the target strength ( $\geq 1.0 \mathrm{MPa}$ ). The long-term (360 days) compressive strength also shows an increasing trend.

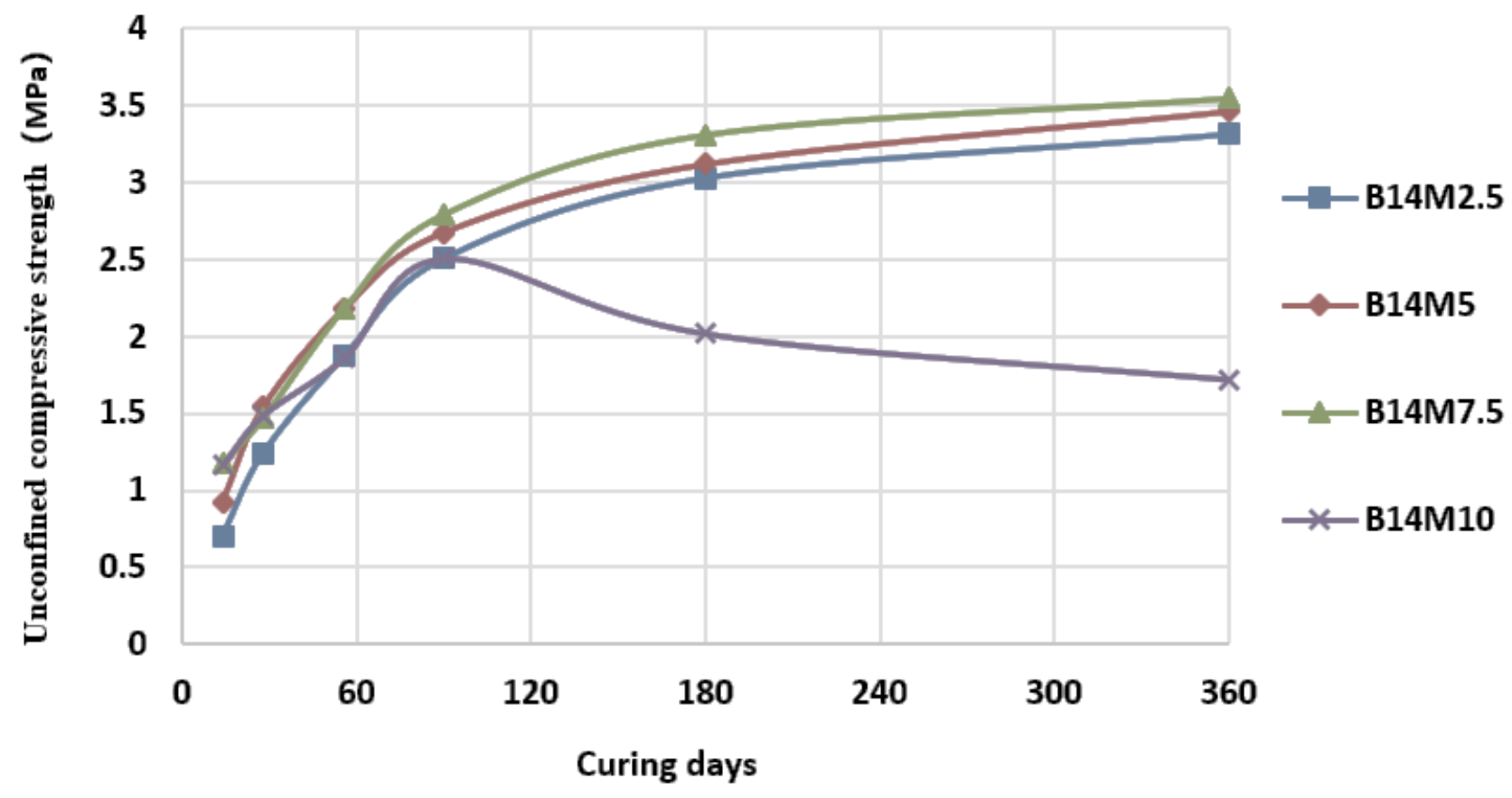

Figure 3 Impact of MgO content on UCS of cemented backfill body

\subsection{Effect of $\mathrm{MgO}$ content on shrinkage/expansion rate of cemented backfill body}

Figure 4 shows the impact of MgO content on the shrinkage/expansion rate of the cemented backfill body. At a MgO-GGBS dosage of $14 \%$ and reactive $\mathrm{MgO}$ contents of 2.5, 5.0 and $7.5 \%$, the cemented backfill body first shrinks and then expands volumetrically. There are generally three phases. The first phase is during the early 14 days, when the cemented backfill body shrinks slightly, with the maximum shrinkage rate less than $0.02 \%$. The second phase is from 14 to 120 days, during which the cemented backfill body begins to expand slightly, and the MgO-GGBS in the body undergoes hydration reaction in the curing box with constant temperature and humidity. Specifically, the MgO hydration reaction has the effect of volumetric expansion, and this process lasts until 120 days. The third phase comes after 120 days, when the relatively low content of reactive $\mathrm{MgO}$ in MgO-GGBS has all reacted. The cemented backfill body continues to expand slightly from 120 to day 360 . At 360 days, the expansion rate of the cemented backfill body is $0.032,0.034$ and $0.045 \%$, corresponding to reactive $\mathrm{MgO}$ contents of 2.5, 5.0 and 7.5\%, respectively. At 14\% MgO-GGBS dosage and $10 \%$ reactive $\mathrm{MgO}$ content, the cemented backfill body shows a volumetric variation trend as follows: rapid volumetric expansion (expansion rate of $0.040 \%$ at 21 days) from demoulding ( 7 days) to 21 days; continuous expansion (expansion rate approaching $0.08 \%$ at 90 days); and further expansion when cured to 360 days (expansion rate reaching $0.104 \%$ ), showing a trend of continual expansion. 


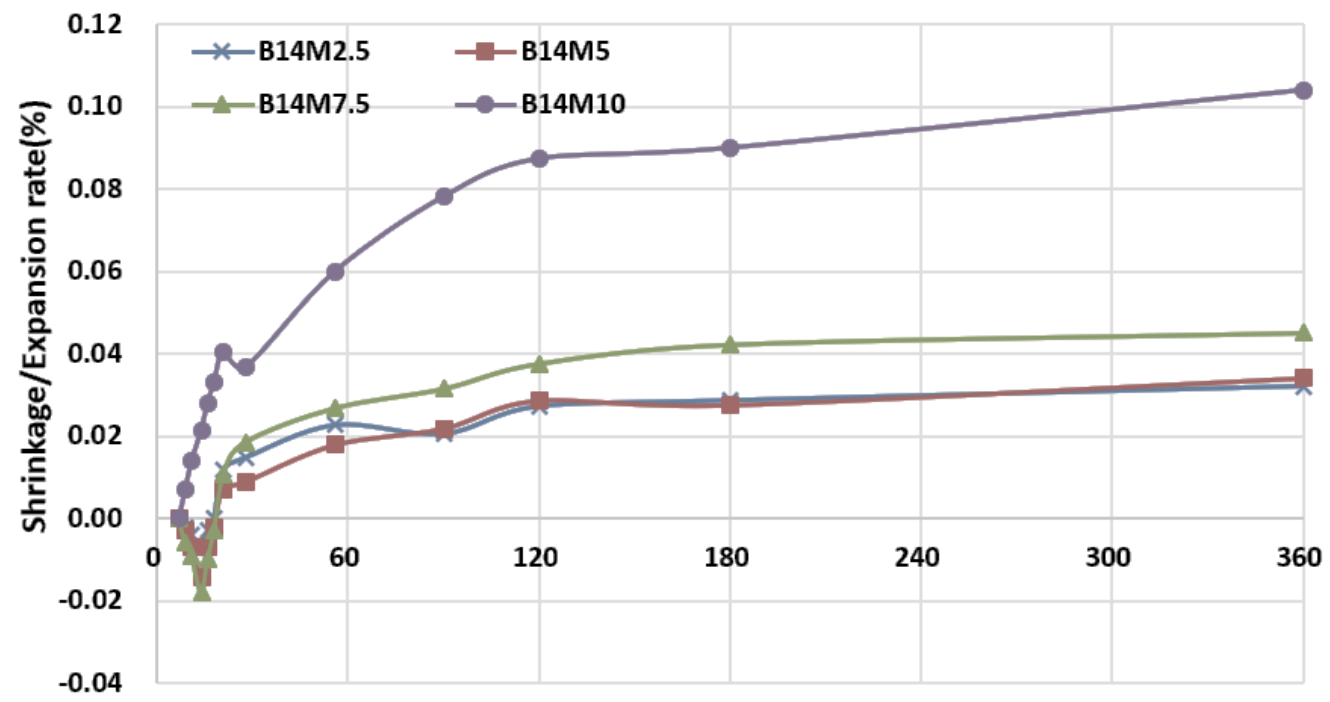

Curing days

Figure 4 Impact of $\mathrm{MgO}$ content on the variation of the shrinkage/expansion rate of the cemented backfill body with curing age

\subsection{Theoretical analysis}

\subsubsection{XRD analysis}

Figure 5 shows the XRD profile of the cemented backfill body at 28 and 56 days, with 14\% MgO-GGBS dosage and reactive $\mathrm{MgO}$ contents of 2.5 and $10 \%$. In addition to the main crystal phases of tailings (C: calcite; P: pyrite; Q: quartz; D: dolomite; and M: mirrorstone), the main hydration products of the cemented backfill body are hydrated calcium silicate (C-S-H) and a hydrotalcite-like ( $\mathrm{Ht}$ ) phase. The $\mathrm{C}-\mathrm{S}-\mathrm{H}$ is found as amorphous colloids showing extremely poor crystallinity, which remains at a low level even after a long time. Therefore, the characteristic peak in the XRD spectrum is very weak, and so it is the typical peak for the $\mathrm{Ht}$ phase. The crystallinity is rather weak, even though tailings usually contain various crystalline materials. High contents of these materials result in high spectrum peaks and frequent overlapping of spectral lines. Moreover, the content of the newly generated hydration products is relatively low, and thus it is difficult to identify from the XRD spectrum.

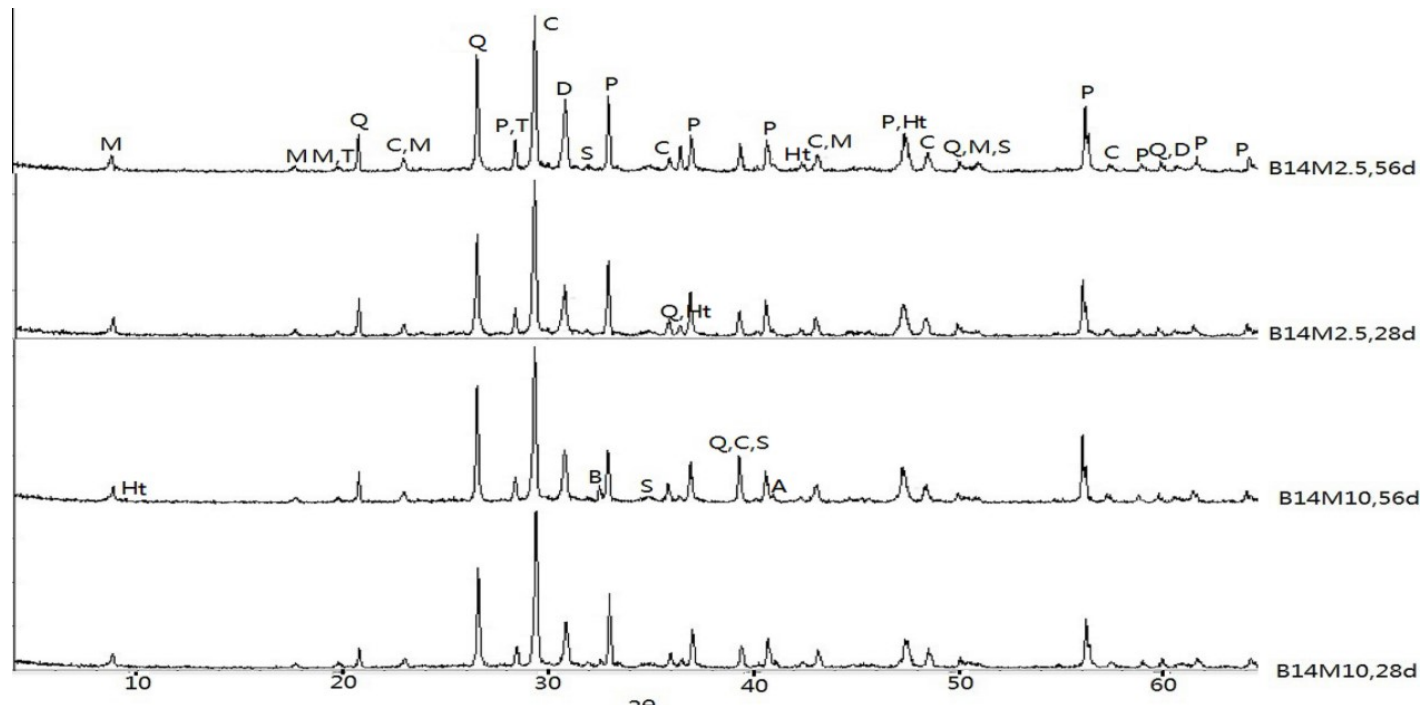

Figure 5 XRD profiles of cemented backfill body where $A=M g O, B=$ magnesite, $C=$ calcite, $P=$ pyrite, $\mathrm{Q}=$ quartz, $\mathrm{D}=$ dolomite, $\mathrm{M}=$ mirrorstone, $\mathrm{T}=$ talc $(\mathrm{M}-\mathrm{S}-\mathrm{H}), \mathrm{Ht}=$ hydrotalcite-like phases, $\mathrm{S}=\mathrm{C}-\mathrm{S}-\mathrm{H}$ 
Figure 5 also shows that there is an apparent characteristic peak of magnesite at $2 \theta=32.3^{\circ}$ when $\mathrm{MgO}$ content is $10 \%$ (i.e. the B14M10 group) and that the 56 -day characteristic peak is much stronger than the 28-day characteristic peak. For the proportion of B14M2.5 (i.e. MgO content 2.5\%), the characteristic peak of magnesite is found neither in the 28-day nor the 56-day XRD spectrum. This is because there is no excessive residual $\mathrm{MgO}$ in the cemented backfill body when the reactive $\mathrm{MgO}$ content is low. Once the responsive $\mathrm{MgO}$ content reaches $10 \%$, excessive $\mathrm{MgO}$ reacts with $\mathrm{CO}_{2}$ and water in the air and generates magnesite $\left(\mathrm{MgCO}_{3}\right)$.

The 28-day hardened MgO-GGBS paste (water-tailings ratio of 0.43 ) was subjected to XRD analysis to further understand the hydration products of MgO-GGBS in the cemented backfill body. As shown in Figure 6, the broad and diffuse peak at $25-35^{\circ} 2 \theta$ reflects the short-range order of the $\mathrm{CaO}-\mathrm{Al}_{2} \mathrm{O}_{3}-\mathrm{MgO}-\mathrm{SiO}_{2}$ glass structure of the GGBS. Various peaks for the tobermorite-like phase (C-S-H) were detected at $2 \theta=\sim 29.5^{\circ}, \sim 30.5^{\circ}$ and $\sim 33.8^{\circ}$. The intensity of the $\mathrm{C}-\mathrm{S}-\mathrm{H}$ phase decreased with the increase of $\mathrm{MgO}$ content in the MgO-GGBS paste. Newly formed peaks of hydrotalcite-like $(\mathrm{Ht})$ at $2 \theta=11.7^{\circ}, 22.3^{\circ}$ and $38^{\circ}$ were found. The height of the $\mathrm{Ht}$ phase characteristic peak increases proportionally with $\mathrm{MgO}$ content, indicating that the addition of more reactive $\mathrm{MgO}$ is favourable for $\mathrm{Ht}$ formation. This is consistent with the research of Ben Haha et al. (2011). The characteristic peak of M-S-H (talc) is observed at $2 \theta=9.2^{\circ}$, for which the MgO content is $2.5 \%$. Such observation is most evident at 28 days, indicating that for low reactive $\mathrm{MgO}$ content, $\mathrm{M}-\mathrm{S}-\mathrm{H}$ products are generated as the curing age increases. The characteristic peak for $\mathrm{MgO}$ was identified regardless of $\mathrm{MgO}$ addition indicating the incomplete hydration of reactive $\mathrm{MgO}$, and the height of the $\mathrm{MgO}$ phase marked peak increases proportionally with $\mathrm{MgO}$ content.

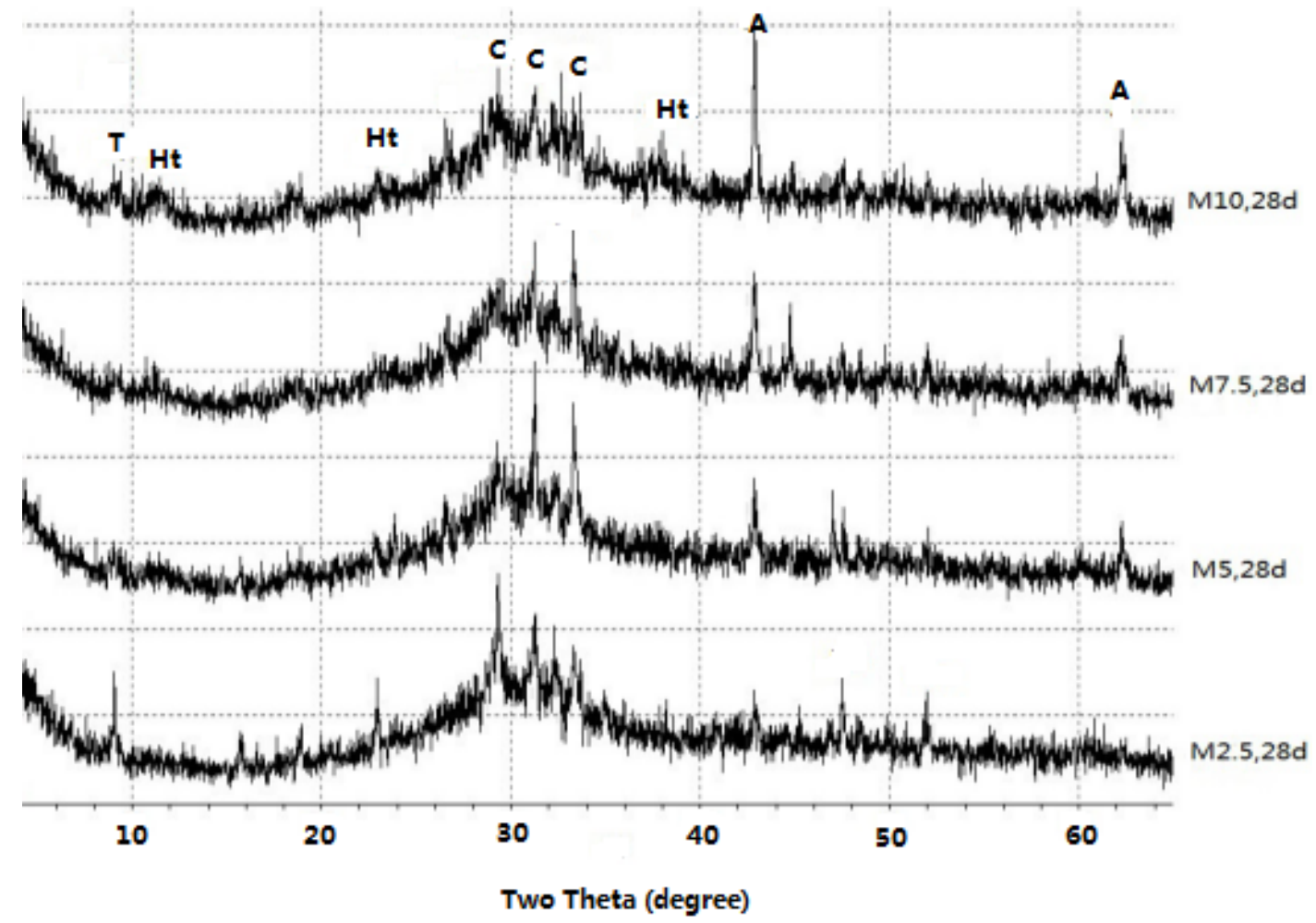

Figure 6 XRD profiles of MgO-GGBS paste where $\mathrm{A}=\mathrm{MgO}, \mathrm{T}=\mathrm{M}-\mathrm{S}-\mathrm{H}$ (talc), $\mathrm{Ht}=$ hydrotalcite-like, $\mathrm{C}=\mathrm{C}-\mathrm{S}-\mathrm{H}$

The result of XRD examination is consistent with previous studies. The hydrated calcium silicate/hydrated magnesium silicate ( $\mathrm{C}-\mathrm{S}-\mathrm{H} / \mathrm{M}-\mathrm{S}-\mathrm{H})$ and $\mathrm{Ht}$ phase are shown as the main hydration products from alkali-activated slags in the presence of Mg (Amaral et al. 2010; Ben Haha et al. 2011; Li et al. 2010). Combining Figures 5 and 6 shows that the cemented backfill body and hardened MgO-GGBS paste in this study have the same species of hydration products, indicating that pyrite $\left(\mathrm{FeS}_{2}\right)$ in tailings does not participate in the hydration reaction. 


\subsubsection{Scanning electron microscope analysis}

Figure 7 shows the SEM images of the cemented backfill body with $14 \%$ MgO-GGBS dosage in the presence of reactive $\mathrm{MgO}$ contents of 2.5 and $10 \%$ at curing ages of 28 and 56 days.

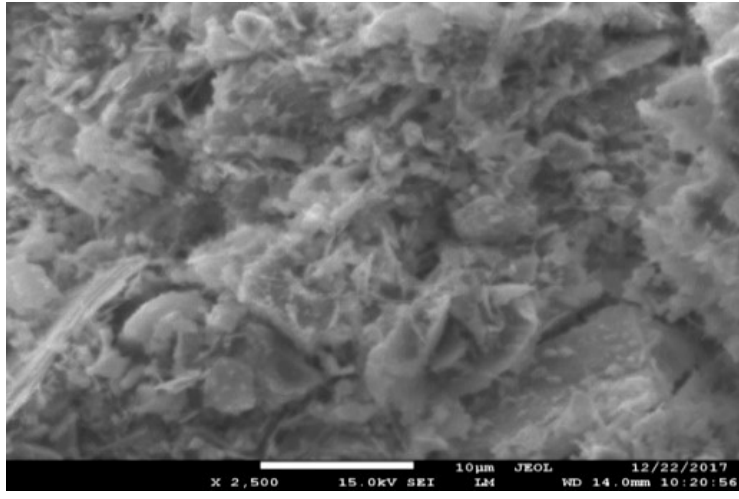

B14M2.5-28d

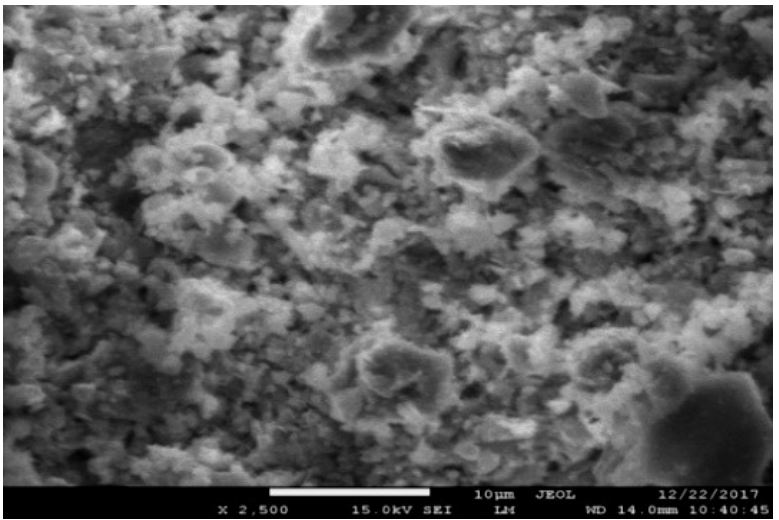

B14M10-28d

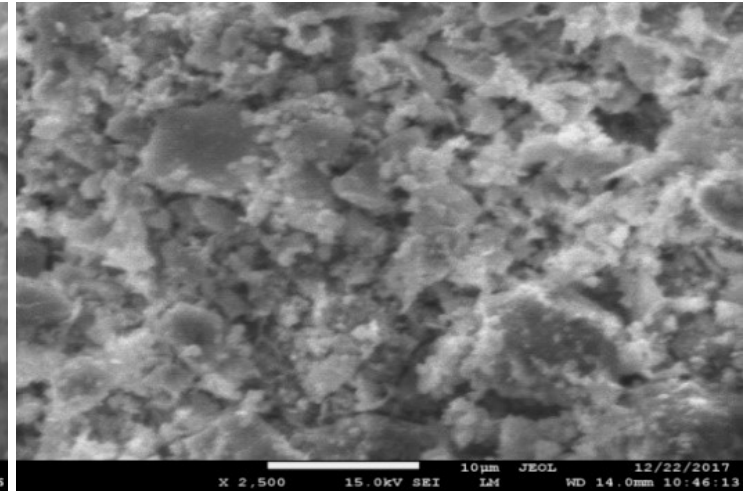

B14M2.5-56d

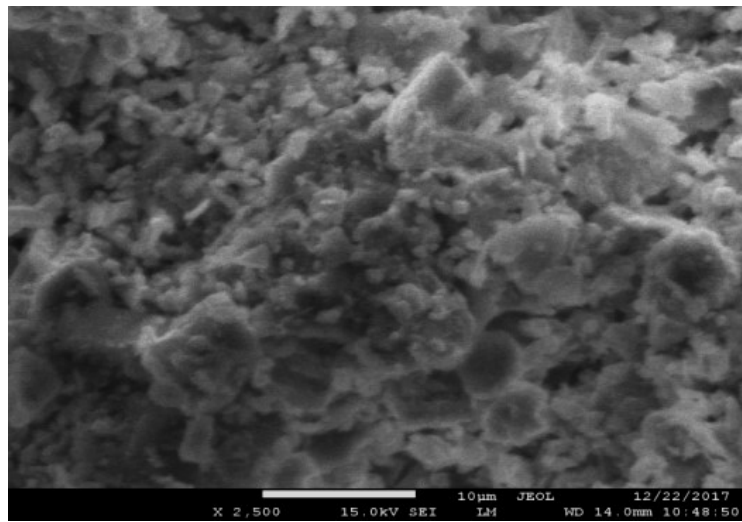

B14M10-56d

Figure 7 Scanning electron microscope images of cemented backfill body

As can be seen, the B14M2.5 cemented backfill body has a relatively loose structure after 28 days of curing. The pores are large, and there are only a few white flocculated hydration products on the particle surface of the tailings. Interparticle pores are obvious. The cemented backfill body structure becomes denser after 56 days of curing, and many more white flocculated hydration products cover the particle surface. For both B14M2.5 and B14M10, particles are well cemented, but the grain contour of tailings is still visible, indicating an open-porous microstructure. With the same curing age (28 or 56 days), B14M10 has a denser microstructure than B14M2.5.

Before 56 days, B14M10 has a higher compressive strength than B14M2.5 in Figure 3, which is attributed to the microstructure. With the same MgO-GGBS dosage, in the early stage, the higher the content of reactive $\mathrm{MgO}$, the greater the UCS; this is because the microstructure becomes denser when pores are filled during the process of hydration and volumetric expansion of $\mathrm{MgO}$. However, considering the dense microstructure, an excessively high $\mathrm{MgO}$ content will result in continual hydration and increase, which eventually damage the microstructure and can consequently reduce the UCS of the cemented backfill body.

The hydration reaction of reactive $\mathrm{MgO}$ in MgO-GGBS has two effects. On the one hand, the hydration reaction of reactive $\mathrm{MgO}$ provides an alkaline environment followed by the breakdown of the covalent bonds (Si-O-Si and Al-O-Si) in GGBS particles to generate hydration products, which fill up the pores of tailing particles and densify the cemented backfill body. On the other hand, the hydration reaction of reactive MgO has the effect of volumetric expansion. As cemented backfill bodies have open-porous microstructures, the slight increase caused by the hydration reaction of reactive MgO in MgO-GGBS can densify the microstructure in the early stage, which enhances the early stage UCS of the cemented backfill body. Nevertheless, when 
the expansion reaction continues to the next stage, it can damage the microstructure of the cemented backfill body and consequently reduce the UCS of the body. It is concluded that the mechanical and expansion properties of cemented backfill body are highly dependent on the reactive MgO content of MgO-GGBS. Since the responsive $\mathrm{MgO}$ content of $\mathrm{MgO}-\mathrm{GGBS}$ can be controlled, the mechanical and expansion properties of cemented backfill body can be controlled or adjusted. Hence, MgO-GGBS is a promising binder for tailings with sulphide.

\section{Conclusion}

The UCS of the cemented backfill body increased with a higher MgO-GGBS content (in total solid mass) and, in particular, an increase in $\mathrm{MgO}$ content (total mass percentage in MgO-GGBS) from 2.5-5\%, 7.5 and $10 \%$.

At a MgO-GGBS dosage of $14 \%$ and reactive MgO content of $2.5-7.5 \%$, the 28 -day UCS of the cemented backfill body achieved the target strength ( $\geq 1.0 \mathrm{MPa}$ ). Further, the long-term (360 day) UCS increased by $141-166 \%$ compared to the UCS at 28 days. At a reactive MgO content of $10 \%$, the compressive strength of the cemented backfill body began to decrease from 90 days until 360 days and suffered a total loss of $31.4 \%$.

At $14 \%$ MgO-GGBS dosage and reactive MgO contents of 2.5, 5.0 and 7.5\%, the cemented backfill body first shrunk and then expanded volumetrically. Starting from 120 days, the backfill body reached its volumetric stability with slight expansion. Until 360 days, the expansion rate of the cemented backfill body was 0.032 , 0.034 and $0.045 \%$, respectively. At $14 \% \mathrm{MgO}-$ GGBS dosage and $10 \%$ reactive $\mathrm{MgO}$ content, the cemented backfill body showed a volumetric variation trend as follows: rapid volumetric expansion (expansion rate of $0.040 \%$ at 21 days) from seven to 21 days; continuous development (expansion rate approaching $0.08 \%$ at 90 days); and further expansion when cured to 360 days (expansion rate reaching $0.104 \%$ ) and showing a trend of continual increase.

Microanalysis revealed that when reactive MgO-GGBS was used as a binder in cemented backfill bodies with sulphide-bearing mine tailings, the main hydration products were $\mathrm{C}-\mathrm{S}-\mathrm{H} / \mathrm{M}-\mathrm{S}-\mathrm{H}$ and $\mathrm{Ht}$. The MgO hydration reaction has the effect of volumetric expansion. The early stage slight increase densifies the microstructure, which enhances the UCS of the cemented backfill body, while the later stage increase damages the microstructure and thus reduces the UCS of the cemented backfill body.

\section{Acknowledgement}

This research was supported by the International Science and Technology Cooperation Program of China (no. 2017YFE0107000), the National Key Research and Development Program of China (no.2016YFC0600709), the Youth Science and Technology Innovation Fund Project of BGRIMM (no.Q-28), the National Key Research and Development Program of China (no.YS2017YFGH000511) and the National Natural Science Foundation of China (no. 51274174).

\section{References}

Amaral, LF, Oliveira, IR, Saloma, R, Frollini, E \& Pandolfelli, VC 2010, 'Temperature and common-ion effect on magnesium oxide (MgO) hydration', Ceramics International, vol. 36, pp. 1047-1054.

Bao, W \& Huyuan, Z 2007, 'Long-term deterioration of cemented paste backfill due to sulphide oxidation', Industrial Minerals and Processing, vol. 10, pp. 29-31 (in Chinese).

Ben Haha, M, Lothenbach, B, Le Saout, G \& Winnefeld, F 2011, 'Influence of slag chemistry on the hydration of alkali-activated blast-furnace slag - part 1: effect of $\mathrm{MgO}^{\prime}$, Cement and Concrete Research, vol. 41, pp. 955-963.

Benzaazoua, M, Belem, T \& Bussiere, B 2002, 'Chemical factors that influence the performance of mine sulphidic paste backfill', Cement and Concrete Research, vol. 32, pp. 1133-1144.

Benzaazoua, M, Ouellet, J, Servant, S, Newman, P \& Verburg, R 1999, 'Cementitious backfill with high sulphur content: physical, chemical, and mineralogical characterization', Cement and Concrete Research, vol. 29, no. 5, pp. 719-725.

Ercikdi, B, Clanger, F \& Kesimal, A 2010, 'Utilization of water-reducing admixtures in cemented paste backfill of sulphide-rich mill tailings', Journal of Hazardous Materials, vol. 179, pp. 940-946.

Ercikdi, B, Kesimal, A \& Cihangir, F 2009, 'Utilization of industrial waste products as a pozzolanic material in cemented paste backfill of high sulphide mill tailings', Journal of Hazardous Materials, vol. 168, issues 2-3, pp. 848-856. 
GB 1999, GB/T 17671-1999 Method of Testing Cements-determination of Strength, Standardization Administration of China, http://www.isosand.com/products/GBT17671-1999.pdf.

ISO 2005, ISO 15901-1:2005 Pore Size Distribution and Porosity of Solid Materials by Mercury Porosimetry and Gas Adsorption Part 1: Mercury Porosimetry, International Organization for Standardization, https://www.iso.org/standard/39385.html

Jiaguo, H \& Desheng, G 2003, 'A research on cemented filling of tailings at Tongshan Copper Mine', Non-ferrous Metals, vol. 55, issue 4, pp. 127-130.

Jin, F, Gu, K \& Al-Tabbaa, A 2014, 'Strength and drying shrinkage of reactive MgO modified alkali-activated slag paste', Construction and Building Materials, vol. 51, pp. 395-404.

Jin, F, Gu, K \& Al-Tabbaa, A 2015, 'Strength and hydration properties of reactive MgO-activated ground granulated blast-furnace slag paste', Cement \& Concrete Composites, vol. 57, pp. 8-16.

Kesimal, A, Yilmaz, E \& Ercikdi, B 2004, 'Evaluation of paste backfill mixtures consisting of sulphide-rich mill tailings and varying cement contents', Cement and Concrete Research, vol. 34, pp. 1817-1822.

Li, C, Sun, H \& Li, L 2010, 'A review: the comparison between alkali-activated slag ( $\mathrm{Si}+\mathrm{Ca}$ ) and metakaolin (Si+Al) cements', Cement and Concrete Research, vol. 40, pp. 1341-1349.

Qinhua, L, Huili, L \& Yanping, B 2017, 'An analysis on forms and potential migration capacity of heavy metals in tailings, Huanjiang, Guangxi province', Industrial Safety and Environmental Protection, vol. 43, issue 1, pp. 33-35.

Shiyang, T 2015, 'A review on heavy metal pollution in basins near the Dabao Mountain mining area', Journal of the Graduates Sun Yat-Sen University, vol. 36, issue 1, pp. 1-7.

Ying, C, Binghui, C \& Qi, Z 2018, 'Distribution of heavy metals in water-surface sediments in AMD, Dabao Mountain in North Guangdong province and influential factors', Journal of Environmental Sciences, vol. 38, issue 1, pp. 134-141.

Zheng, J, Guo, L, Sun, X, Li, W \& Jia, Q 2018, 'Study on the strength development of cemented backfill body from lead-zinc mine tailings with sulphide', Advances in Materials Science and Engineering, vol. 2018, pp. 1-8.

Zheng, J, Guo, L \& Zhao, Z 2017, 'Effect of calcined hard kaolin dosage on the strength development of CPB of fine tailings with sulphide', Advances in Materials Science and Engineering, vol. 2017, pp. 1-7.

Zheng, J, Zhu, Y \& Zhao, Z 2016, 'Utilization of limestone powder and water-reducing admixture in cemented paste backfill of coarse copper mine tailings', Construction and Building Materials, vol. 124, pp. 31-36. 